BNL-112756-2016-JA

\title{
The role of organic solvent radical cations in separations ligand degradation
}

\author{
Stephen P Mezyk, Bruce J. Mincher, \\ Surajdevprakash B. Dhiman, Bobby Layne, and James F. Wishart
}

Submitted to Journal of Radioanalytical and Nuclear Chemistry

March 2016

Chemistry Department

Brookhaven National Laboratory

\author{
U.S. Department of Energy \\ USDOE Office of Science (SC), \\ Basic Energy Sciences (BES) (SC-22)
}

Notice: This manuscript has been authored by employees of Brookhaven Science Associates, LLC under Contract No. DE- SC0012704 with the U.S. Department of Energy. The publisher by accepting the manuscript for publication acknowledges that the United States Government retains a non-exclusive, paid-up, irrevocable, world-wide license to publish or reproduce the published form of this manuscript, or allow others to do so, for United States Government purposes. 


\section{DISCLAIMER}

This report was prepared as an account of work sponsored by an agency of the United States Government. Neither the United States Government nor any agency thereof, nor any of their employees, nor any of their contractors, subcontractors, or their employees, makes any warranty, express or implied, or assumes any legal liability or responsibility for the accuracy, completeness, or any third party's use or the results of such use of any information, apparatus, product, or process disclosed, or represents that its use would not infringe privately owned rights. Reference herein to any specific commercial product, process, or service by trade name, trademark, manufacturer, or otherwise, does not necessarily constitute or imply its endorsement, recommendation, or favoring by the United States Government or any agency thereof or its contractors or subcontractors. The views and opinions of authors expressed herein do not necessarily state or reflect those of the United States Government or any agency thereof. 
2 Names of the authors: Stephen P. Mezyk, Bruce J. Mincher, Suraidevprakash B. Dhiman, Bobby Layne, James F. Wishart.

4 Title: The role of organic solvent radical cations in separations ligand degradation

5 Stephen P. Mezyk, Department of Chemistry and Biochemistry, California State

6 University at Long Beach, 1250 N. Bellflower Blvd., Long Beach, CA, 90840, USA.

8 Bruce J. Mincher, Idaho National Laboratory, Idaho Falls, ID, 83415-4107 USA

10 Surajdevprakash B. Dhiman, Chemistry Department, Brookhaven National Laboratory, 11 Upton NY, 11973-5000, USA.

12

13 Bobby Layne, Chemistry Department, Brookhaven National Laboratory, Upton NY, 14 11973-5000, USA.

16 James F. Wishart, Chemistry Department, Brookhaven National Laboratory, Upton NY, 17 11973-5000, USA.

18 E-mail address of the corresponding author: Stephen.Mezyk@csulb.edu 

separations ligand degradation

\title{
The role of organic solvent radical cations in
}

\author{
Stephen P Mezyk ${ }^{1}$, Bruce J. Mincher²,
}

\begin{abstract}
Surajdevprakash B. Dhiman $^{3}$, Bobby Layne ${ }^{3}$, James F. Wishart ${ }^{3}$
${ }^{1}$ Department of Chemistry and Biochemistry, California State University at Long Beach, 1250 N. Bellflower Blvd., Long Beach, CA, 90840, USA.

${ }^{2}$ Idaho National Laboratory, Idaho Falls, ID, 83415-4107 USA

${ }^{3}$ Chemistry Department, Brookhaven National Laboratory, Upton NY, 11973-5000, USA
\end{abstract}

\section{Abstract}

30 The dodecane radical cation reaction rate constant with CMPO was measured using ps

31 electron pulse radiolysis/absorption spectroscopy as $\mathrm{k}=(1.30 \pm 0.11) \times 10^{10} \mathrm{M}^{-1} \mathrm{~s}^{-1}$ in

32 dodecane/0.10 $\mathrm{M} \mathrm{CH}_{2} \mathrm{Cl}_{2}$ solution. No reactivity increase occurred when these solutions

33 were pre-contacted with nitric acid, similar to the behavior observed for TODGA. To

34 corroborate these kinetic data with steady-state radiolysis measurements, where acid pre-

35 contacted CMPO showed significantly less degradation, it is proposed that the dodecane

36 radical cation always reacts directly with TODGA, but for CMPO the charge-transfer

37 occurs with the $\mathrm{CMPO} \bullet \mathrm{HNO}_{3}$ complex formed in the acid contacted solvent.

$38 \quad$ Keywords

39 Dodecane radical cation, ps pulse radiolysis, CMPO, TODGA, acid contact 


\section{Introduction}

41 The neutral, organophosphorous amide octylphenyl-N,N-diisobutylcarbamoylmethyl

42 phosphine oxide (CMPO) (Fig. 1) is an important ligand used to complex actinides and

43 lanthanides both in analytical chemistry and in proposed nuclear fuel cycle applications.

44 It was originally designed for use in the TRUEX (TRansUranium Extraction) process,

45 where the highly basic phosphoryl group complexes trivalent actinides and lanthanides,

46 while the carbamoyl group was reputed to complex nitric acid thus allowing for metal

47 complexation even in highly acidic solution. [1] The TRUEX process was designed to

48 remove trivalent actinides such as americium from high level waste, and has more

49 recently been recommended for americium extraction from dissolved nuclear fuel. In

50 either application the CMPO-containing solvent would see high radiation doses, and thus

51 the stability of the ligand and the nature of its degradation products are of importance.

52 The gamma-ray radiolysis of CMPO has been previously investigated with regard to its

53 degradation products and G-values for decomposition, [2-6] however, there are only three

54 reports concerning the alpha-radiolysis of CMPO, including one from this journal. [7-9]

56

57

58

59

60 Radiolysis of the biphasic solvent extraction system produces a complex suite of radical

61 species which may have deleterious effects on the ligand. Among the species produced in

62 the aqueous phase are the reactive products of water and nitric acid radiolysis: [10, 11]

63

$$
\mathrm{H}_{2} \mathrm{O} \stackrel{\text { radiation }}{\longrightarrow} \cdot \mathrm{OH}+{ }^{\circ} \mathrm{H}+\mathrm{e}_{\mathrm{aq}}{ }^{-}+\mathrm{H}_{2}+\mathrm{H}_{2} \mathrm{O}_{2}+\mathrm{H}_{3} \mathrm{O}^{+}
$$

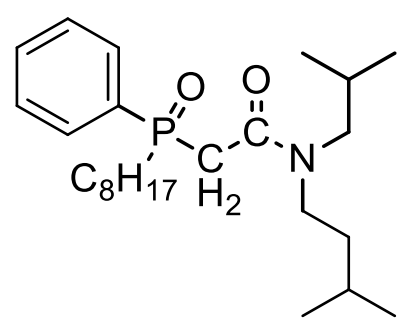

Fig. 1. Chemical structures of CMPO (left) and TODGA (right).

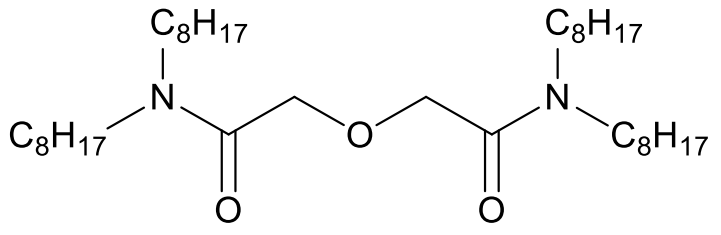


65 The irradiation of the organic phase produces various neutral and ionic carbon-centered 66 radicals: [12]

$$
+{ }^{\cdot} \mathrm{CH}_{3}+{ }^{\cdot} \mathrm{H}+\mathrm{H}_{2}
$$

69 The effect of these produced reactive species on CMPO will depend on the kinetics of the 70 reaction of each with the ligand, expressed as a bimolecular rate constant $k$, as those 71 reactions occur in competition with other species in solution. In the acidic, aerated, 72 aqueous phase, various scavenging reactions will remove the reducing $\mathrm{e}^{-}$aq and most ${ }^{\circ} \mathrm{H}$ 73 atom from further consideration. [13] Thus, the oxidizing ${ }^{\circ} \mathrm{OH}$ and ${ }^{\circ} \mathrm{NO}_{3}$ radicals are most 74 important in the aqueous phase.

75 In the organic phase comparatively less is understood about the impact of radiation. The 76 organic phase diluent for TRUEX applications is dodecane, and thus an important 77 product species on the organic side is the dodecane radical cation. Little is known of the 78 reactions of this species. Sugo et al. postulated that it is a reactant that could undergo 79 electron transfer reactions with the amidic fuel cycle ligand tetraoctyldiglycolamide 80 (TODGA, Fig. 1), [14, 15] and Zarzana et al. reported the rate constant for the TODGA 81 reaction with this species to be diffusion limited. [16] However, no corresponding work 82 has been done for CMPO. Here we report the measurement of dodecane radical cation 83 reactions with CMPO, both in the pure organic phase and when in contact with aqueous 84 nitric acid. The results are compared to our previous reports of the rates of CMPO 85 degradation in gamma-irradiations under similar solution conditions, where it was 86 observed that pre-contact of nitric acid provided a protecting effect of CMPO 87 degradation. [6] The decrease in the CMPO degradation rate (-GCMPO) was attributed to 88 the protective effect of the formation of a $\mathrm{CMPO} \bullet \mathrm{HNO}_{3}$ complex in dodecane [6]

$$
\mathrm{HNO}_{3}(\mathrm{aq})+\mathrm{CMPO}(\text { org }) \leftrightharpoons \mathrm{CMPO} \bullet \mathrm{HNO}_{3}(\text { org }) \quad \mathrm{K}_{4}=0.15 \pm 0.01
$$


90 which had been identified by mass spectrometry. [17, 18] This protection was not 91 observed for TODGA, indicating that an equivalent nitric acid complex was not formed

92 in the organic phase. [16]

93 The goal of this work was to further investigate the chemistry involved in ligand 94 degradation occurring in the organic phase due to the dodecane radical cation. In 95 particular, we wanted to determine whether the charge transfer kinetics of this cation 96 were altered for CMPO when it had been pre-contacted with nitric acid.

\section{Experimental}

98 Ligands (CMPO and TODGA) were supplied from Idaho National Laboratory at the

99 highest purity commercially available. Dodecane and methylene chloride (Sigma-

100 Aldrich) were $>99 \%$ purity. Picosecond electron pulse radiolysis/transient absorption 101 experiments were performed at the Brookhaven LEAF facility, as described previously. 102 [19] Samples were irradiated in $1.00 \mathrm{~cm}$ Suprasil semimicro cuvettes sealed with Teflon 103 stoppers. The doses per pulse for various experiments were in the range 20-40 Gy. 104 Time-resolved kinetics were obtained using a FND-100 silicon diode detector and 105 digitized using a LeCroy WaveRunner 640Zi oscilloscope (4GHz, 8 bit). 106 Interference filters ( 10 nm bandpass) were used for the wavelength selection of the 107 analyzing light.

108 Acid contacted measurements were performed on dodecane solutions after equal volumes 109 of dodecane/0.10 $\mathrm{M} \mathrm{CH}_{2} \mathrm{Cl}_{2} /$ ligand and acidic water were hand shaken vigorously for 5 110 minutes followed by gravity phase separation for 10-20 minutes.

\section{Results and discussion}

112 The electron pulse radiolysis of an organic solvent such as dodecane results in a mixture 113 of radical $\left(\mathrm{H}^{*}, \mathrm{C}_{\mathrm{x}} \mathrm{H}_{\mathrm{y}}{ }^{\circ}\right)$ and ionic $\left(\mathrm{e}^{-}\right.$solv, $\left.\mathrm{R}^{+\bullet}\right)$ species formed by the alkane bond breakage 114 and ionization as shown in Equation 3. Under the aerated solution conditions, it is 
115 expected that the solvated electrons would quickly react with the added $0.10 \mathrm{M}$ 116 dichloromethane;

$$
\mathrm{e}_{\text {solv }}^{-}+\mathrm{CH}_{2} \mathrm{Cl}_{2} \rightarrow \mathrm{Cl}^{-}+{ }^{\circ} \mathrm{CH}_{2} \mathrm{Cl}
$$

k5

118 thus eliminating any absorbance interference from this transient. All the carbon-centered

119 radicals (generically listed as $\mathrm{R}^{\bullet}$ ) would react with dissolved oxygen to form relatively 120 inert peroxyl radicals;

$$
\mathrm{R}^{\bullet}+\mathrm{O}_{2} \rightarrow \mathrm{RO}_{2}{ }^{\bullet}
$$

k6

122 Therefore, the most important species remaining that could react with added extractant

123 ligands such as CMPO is expected to be the solvent radical cation, $\mathrm{R}^{+}$. The dodecane 124 radical cation has been previously identified [16] using UV-visible absorption 125 spectroscopy, and its reaction with TODGA quantitatively established. The rate constant 126 for this reaction

$$
\mathrm{C}_{12} \mathrm{H}_{26}{ }^{+\bullet}+\text { TODGA } \rightarrow \mathrm{C}_{12} \mathrm{H}_{26}+\left[\text { TODGA }^{+\cdot}\right] \quad \mathrm{k}_{7}
$$

128 was measured as $\mathrm{k}_{7}=(9.72 \pm 1.10) \times 10^{9} \mathrm{M}^{-1} \mathrm{~s}^{-1}$. [16] However, no equivalent kinetics 129 for CMPO have been reported, nor for any acid contacted ligand-containing solvents. 130 Therefore in this study, the importance of the dodecane radical cation reaction with 131 CMPO, and the impact of nitric acid contract with both CMPO and TODGA was 132 elucidated by measurement of absolute second-order rate constants. Initially, transient 133 absorption spectra were obtained over the visible/near IR wavelength region, as shown in 134 Fig. 2. These spectra show that the same radical cation is initially generated under all 135 conditions, and that the cation is apparently not immediately quenched by nitric acid 136 contact. However, the kinetics of the dodecane radical cation at $800 \mathrm{~nm}$ are seen to decay 137 faster in the presence of increasing amounts of CMPO (Fig. 3). These individual decays 138 were fitted to an exponential decay function, which also included a small baseline 139 adjustment. The pseudo-first-order rate constants obtained were plotted against the 140 CMPO concentration, see Fig. 4, whose slope gave a second-order rate constant for the 141 reaction 


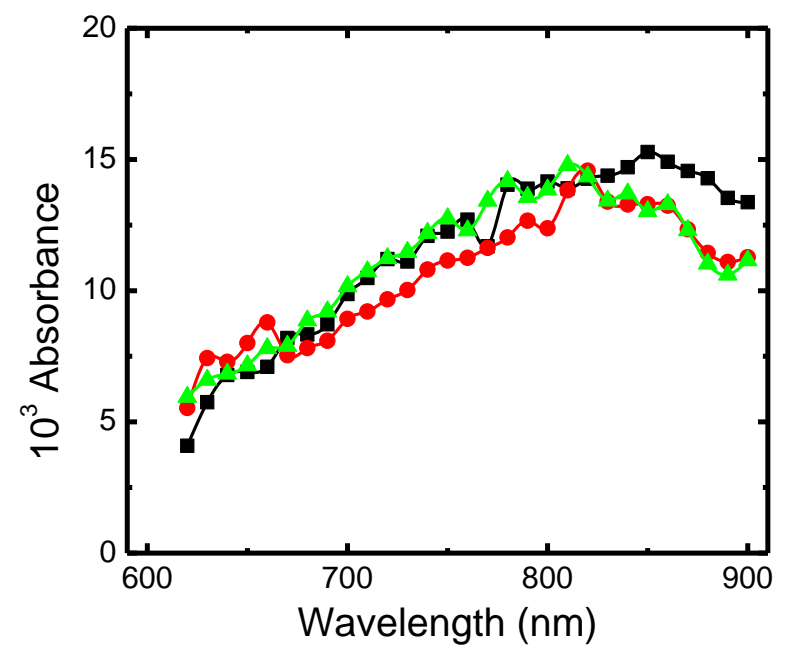

142

143 Fig. 2. Dose normalized initial $(\mathrm{t}=0$, extrapolated $)$ transient intensities for aerated 144 dodecane $(\boldsymbol{\square}), \mathrm{CMPO}$ in dodecane $(\bullet)$ and CMPO in dodecane pre-contacted with $5 \mathrm{M}$ 145 $\mathrm{HNO}_{3}(\boldsymbol{\Delta})$.

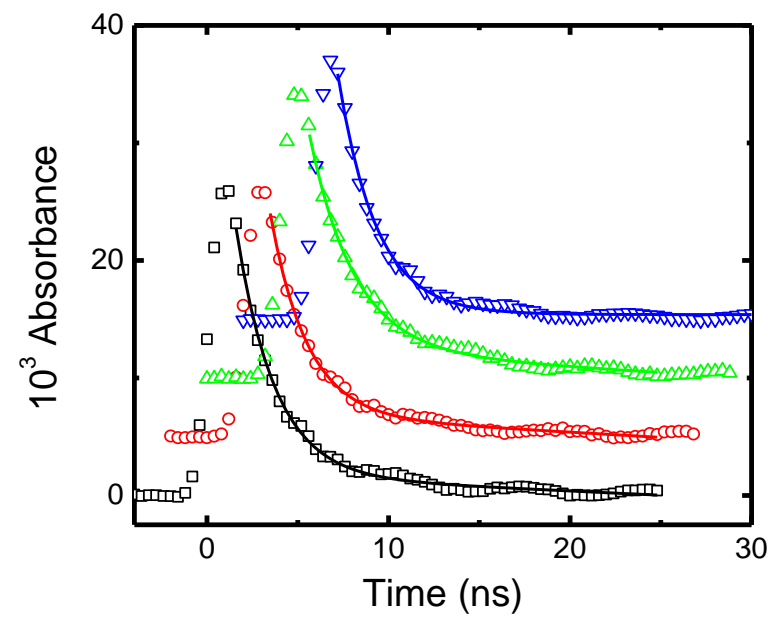

146

147 Fig. 3. Transient kinetics observed at $800 \mathrm{~m} \mathrm{~nm}$ for dodecane radical cation reaction with 148 5-20 mM CMPO. Data offset in both time and absorbance intensity to aid clarity. Solid 149 lines are exponential decay fits, with corresponding first-order rate constants of (5.05 \pm $1500.27) \times 10^{8}(\square, 5 \mathrm{mM}$ CMPO $),(5.48 \pm 0.34) \times 10^{8}(\mathrm{O}, 10 \mathrm{mM} \mathrm{CMPO}),(6.01 \pm 0.66) \times 10^{8}$

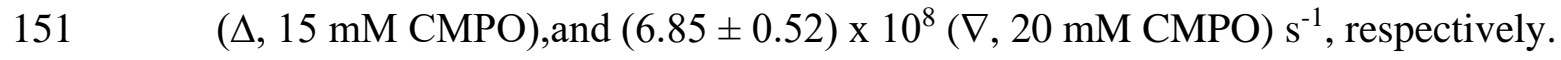



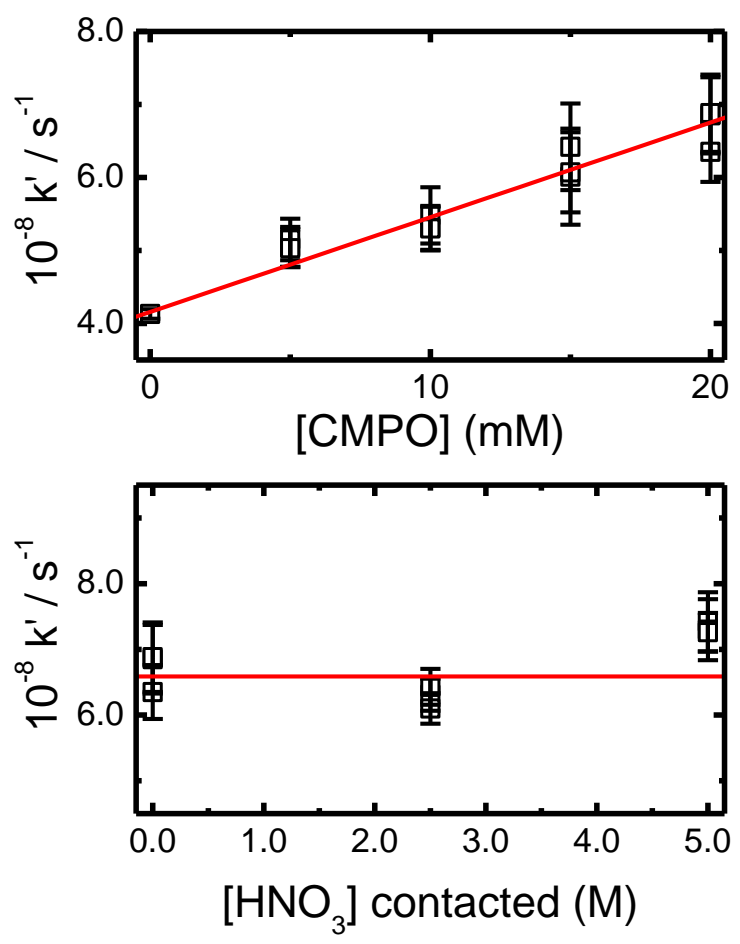

153 Fig. 4. Top: Second-order rate constant plot for reaction of dodecane radical cation $\left(\mathrm{R}^{+\bullet}\right)$ 154 with CMPO in dodecane/0.10 $\mathrm{M} \mathrm{CH}_{2} \mathrm{Cl}_{2}$ at $295 \mathrm{~K}$. Individual data points and 155 corresponding error bars are the average of 3 individual measurements for each CMPO 156 concentration. Solid line is weighted linear fit, corresponding to a slope of $\mathrm{k}_{8}=(1.30 \pm$ $1570.11) \times 10^{10} \mathrm{M}^{-1} \mathrm{~s}^{-1},\left(\mathrm{R}^{2}=0.96\right)$. Bottom: Measured rate constants for $20 \mathrm{mM} \mathrm{CMPO}$ in 158 aerated dodecane/0.10 $\mathrm{M} \mathrm{CH}_{2} \mathrm{Cl}_{2}$ contacted with different nitric acid concentrations showing no significant increase in reactivity.

$$
\mathrm{C}_{12} \mathrm{H}_{26}{ }^{+\bullet}+\mathrm{CMPO} \rightarrow \mathrm{C}_{12} \mathrm{H}_{26}+\left[\mathrm{CMPO}^{\bullet}\right] / \text { other products } \quad \mathrm{k} 8
$$

162 of $\mathrm{k}_{8}=(1.30 \pm 0.11) \times 10^{10} \mathrm{M}^{-1} \mathrm{~s}^{-1}$. This rate constant is slightly faster than the value 163 obtained previously for TODGA.

164 Equivalent kinetic measurements were made for the highest concentration of $20 \mathrm{mM}$ $165 \mathrm{CMPO}$ with two acid pre-contacts, 2.5 $\mathrm{M}$ and 5.0 $\mathrm{M} \mathrm{HNO}_{3}$. These kinetic data are shown 166 in Fig. 4. No significant change in the chemical reaction reactivity was observed. This 

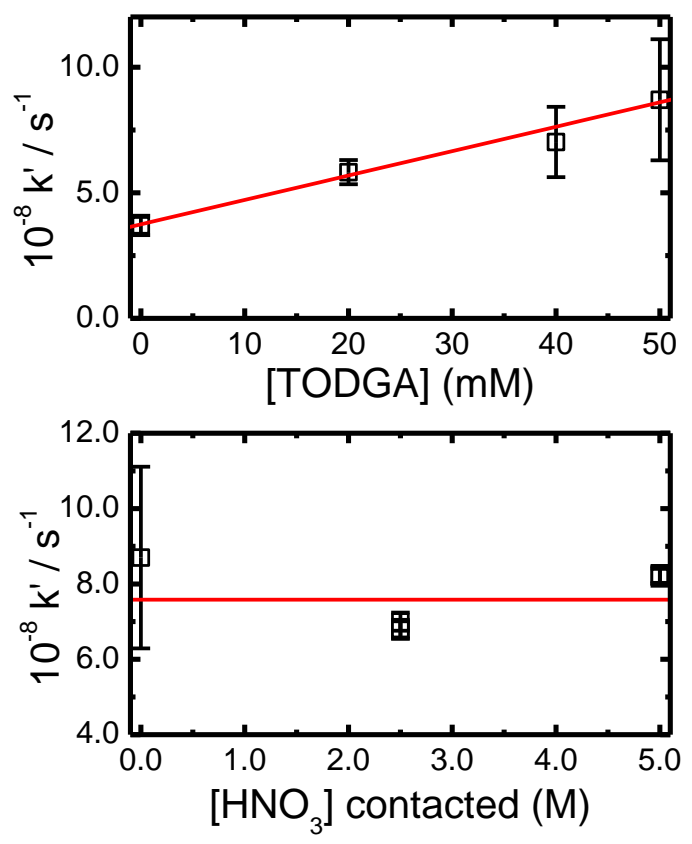

168 Fig. 5. Top: Second-order rate constant determination for dodecane radical cation 169 reaction with TODGA in dodecane/0.10 $\mathrm{M} \mathrm{CH}_{2} \mathrm{Cl}_{2}$ at $295 \mathrm{~K}$. Individual data points and 170 error bars are the average of 2-3 individual measurements for each TODGA 171 concentration. Solid line is weighted linear fit, corresponding to a slope of $\mathrm{k}_{7}=(9.72 \pm$ 172 1.10) x $10^{9} \mathrm{M}^{-1} \mathrm{~s}^{-1},\left(\mathrm{R}^{2}=0.974\right)$. Bottom: Rate constants measured for $50 \mathrm{mM}$ TODGA 173 in aerated dodecane/0.10 $\mathrm{M} \mathrm{CH}_{2} \mathrm{Cl}_{2}$ which had been contacted with different concentrations of nitric acid showing no significant increase in reactivity.

176 constant behavior at various acid concentration contacts is consistent with the 177 interpretation that the charge transfer still occurs at effectively a diffusion controlled rate 178 with the formed nitric acid complex:

$$
\mathrm{C}_{12} \mathrm{H}_{26}{ }^{+\bullet}+\mathrm{CMPO} \bullet \mathrm{HNO}_{3} \rightarrow \mathrm{C}_{12} \mathrm{H}_{26}+\mathrm{CMPO}+\left[\mathrm{HNO}_{3}{ }^{+\bullet}\right] \quad \mathrm{k} 9
$$

180 However, for the -GCMPO data previously reported [6] to be consistent with the measured 181 kinetics, the charge transfer reaction that occurs with the complex would have to have to 
182 regenerate free unchanged CMPO (Reaction 9) whereas the charge transfer with the free

183 CMPO would directly result in ligand degradation (Reaction 8).

184 To further investigate this phenomenon, we also performed equivalent experiments for 185 acid-contacted TODGA, these data are shown in Fig. 5. The non-acid (zero

186 concentration) contact data point was taken from Zarzana et al., [16], the acid-contacted 187 measurements were performed in this study. Again the acid-contact data show minimal 188 reactivity change, as observed for CMPO. This similarity implies that it is not only the 189 presence of acid that is important for ligand protection from dodecane radical cation 190 reaction, but rather the formation of a ligand-nitric acid complex. At this time we are 191 pursuing additional experiments to further verify this.

\section{Conclusions}

193 The dodecane radical cation reaction rate constant with CMPO was directly measured 194 using ps electron pulse radiolysis to be $\mathrm{k}_{8}=(1.30 \pm 0.11) \times 10^{10} \mathrm{M}^{-1} \mathrm{~s}^{-1}$ in dodecane/0.10 $195 \mathrm{M} \mathrm{CH}_{2} \mathrm{Cl}_{2}$. This value is slightly faster than determined for TODGA previously, $\mathrm{k}_{7}=$ $196(9.72 \pm 1.10) \times 10^{9} \mathrm{M}^{-1} \mathrm{~s}^{-1}$. No change in reactivity was observed when these solvents 197 were pre-contacted with nitric acid. These results suggest that the dodecane radical cation 198 charge transfer always occurs directly with free TODGA, but in the case of the CMPO 199 the formation of a $\mathrm{CMPO} \bullet \mathrm{HNO}_{3}$ complex in acid contacted solvent minimizes the 200 charge-transfer induced degradation of this ligand.

\section{Acknowledgements}

202 The radiolysis experiments performed at Brookhaven National Laboratory (BNL) and use 203 of the LEAF Facility of the BNL Accelerator Center for Energy Research were supported

204 by the US-DOE Office of Science, Division of Chemical Sciences, Geosciences and 205 Biosciences under contract DE-SC0012704. Funding was provided by the USDOE 206 Assistant Secretary for NE, under the FCR\&D Radiation Chemistry program; DOE-Idaho 207 Operations Office Contract DE-AC07-05ID14517. 


\section{References}

209 1. Horwitz EP, Kalina DC, Diamond H, Vandegrift GF, Schulz WW, (1985) The TRUEX

210 process - a process for the extraction of transuranic elements from nitric acid wastes

211 utilizing modified PUREX solvent. Solvent Extr Ion Exch 3: 75-109

212 2. Chiarizia R, Horwitz EP, (1986) Hydrolytic and radiolytic degradation of octyl(phenyl)-

213 N,N-diisiobutylcarbamoylmethylphosphine oxide and related compounds. Solvent

$214 \quad$ Extr Ion Exch 4: 677-723

215 3. Nash KL, Gatrone RC, Clark GA, Rickert PG, Horwitz EP, (1988) Hydrolytic and

216 radiolytic degradation of CMPO: Continuing studies. Sep Sci Technol 23: 1355-1372

217 4. Nash KL, Rickert PG, Horwitz EP, (1989) Degradation of TRUEX-dodecane process

218 solvent. Solvent Extr Ion Exch 7: 655-675.

219 5. Mathur JN, Murali MS, Ruikar PB, Nagar MS, Sipahimalani AT, Bauri AK, Banerji A,

220 (1998) Degradation, clean-up and reusability of octylphenyl-N,N'-diisobutyl

221 carbamoylmethyl phosphine oxide (CMPO) during partitioning of minor actinides

222 from high level waste (HLW) solutions. Sep Sci Technol 33: 2179-2196

223 6. Mincher BJ, Mezyk SP, Elias G, Groenewold GS, Olson LG, (2013) The radiation

224 chemistry of CMPO: Part 1. Gamma radiolysis. Solvent Extr Ion Exch 3: 715-730

225 7. Buchholz BA, Nuñez L, Vandegrift GF, (1996) Effect of $\alpha$-radiolysis on TRUEX-NPH

226 solvent. Sep Sci Technol 31: 2231-2243

227 8. Mincher BJ, Mezyk SP, Elias G, Groenewold GS, LaVerne JA, Nilsson M, Pearson J,

228 Schmitt NC, Tillotson RD, Olson LG, (2014) The radiation chemistry of CMPO: Part 2.

$229 \quad$ Alpha radiolysis. Solvent Extr Ion Exch 32: 167-178 
230 9. Mezyk SP, Mincher BJ, Ekberg C, Skarnemark G, (2013) Alpha and gamma radiolysis

231 of nuclear solvent extraction ligands used for An(III) and $\operatorname{Ln}(\mathrm{III})$ separations. J

232 Radioanal Nucl Chem 296: 711-715

233 10. Buxton GV, Greenstock CL, Helman WP, Ross AB (1988) Critical review of rate

234 constants for the reactions of hydrated electrons, hydrogen atoms, and hydroxyl

235 radicals $\left(\bullet \mathrm{OH} / \mathrm{O}^{-}\right)$in aqueous solution. J Phys Chem Ref Data 17: 513-886

236 11. Jiang PY, Nagaishi R, Yotsuyanagi T, Katsamura Y, Ishiguri K, (1994) $\gamma$-radiolysis study

237 of concentrated nitric acid solutions. J Chem Soc Faraday Trans 90: 93-95

238 12. Spinks JWT, Woods RJ, (1991) An Introduction to Radiation Chemistry, $3^{\text {rd }}$ Ed John

239 Wiley and Sons, Hobokken, NJ

240 13. Mincher BJ, Modolo G, Mezyk SP, (2009) The effects of radiation chemistry on

241 solvent extraction: 1. Conditions in acidic solution and a review of TBP radiolysis.

242 Solvent Extr Ion Exch 27: 1-25

243 14. Sugo Y, Sasaki Y, Tachimori S, (2002) Studies on the hydrolysis and radiolysis of

244 N,N,N’N'-teraoctyl-3-oxapentane-1,5-diamide. Radiochim Acta 90: 161-165

245 15. Sugo Y, Izumi Y, Yoshida Y, Nishijima, S, Sasaki Y, Kimura T, Sekine T, Kudo H, (2007)

246 Influence of diluent on radiolysis of amides in organic solution. Radiat Phys Chem 76:

$247 \quad 794-800$

248 16. Zarzana CA, Groenewold GS, Mincher BJ, Mezyk SP, Wilden A, Schmidt H, Modolo G,

249 Wishart JF, Cook AR, (2015) A comparison of the $\gamma$-radiolysis of TODGA and

$250 \quad \mathrm{~T}(\mathrm{EH}) \mathrm{DGA}$ using UHPLC-MS analysis. Solvent Extr Ion Exch 33: 431-437 
251 17. Elias G, Groenewold GS, Mincher BJ, Mezyk SP, (2012) Determination of CMPO and 252 identification of some radiolysis products using HPLC-UV and mass spectrometry. J $253 \quad$ Chromatog A 1243: 47-52

254 18. Groenewold GS, Elias G, Mincher BJ, Mezyk SP, LaVerne JA, (2012) Characterization 255 of CMPO and its radiolysis products by direct infusion ESI-MS, Talanta, 99: 909-917

256 19. Wishart JF, Cook AR, Miller JR, (2004) The LEAF Picosecond Pulse Radiolysis Facility 257 at Brookhaven National Laboratory. Rev Sci Instrum 75: 4359-436 